\title{
THE EFFECT OF INSUFFICIENT IRON CONSUMPTION DURING PREGNANCY ON THE RISK OF LOW BIRTH WEIGHT IN RSUD KOTA DEPOK AND BEKASI
}

\author{
CITRA YULIYANDA PARDILAWATI ${ }^{1}$, SUDIBYO SUPARDI ${ }^{2}$, RETNOSARI ANDRAJATI ${ }^{1 *}$
}

${ }^{1}$ Department of Clinical Pharmacy, Faculty of Pharmacy, Universitas Indonesia, Depok, Indonesia. ${ }^{2}$ Center of Technology Intervention Public Health, Health Research and Development Office, Ministry of Health, Indonesia. Email: andrajati@farmasi.ui.ac.id

Received: 21 April 2017, Revised and Accepted: 13 July 2017

\section{ABSTRACT}

Objective: The purpose of this study was to investigate the effect of low consumption of iron tablets during pregnancy on the risk of low birth weight. This case-control study included 56 women who gave birth to infants weighing < $2500 \mathrm{~g}$ in RSUD Kota Depok and Bekasi. The control group consisted of 112 mothers who gave birth to infants weighing $\geq 2500 \mathrm{~g}$.

Methods: This study was performed from September 2015 to December 2015. Data were collected from patient's medical records and via structured interviews with questionnaires.

Results: We found that, among the study participants, $73.2 \%$ were aged $20-35$ years, $76.2 \%$ had a gestational age $\geq 37$ weeks, $61.3 \%$ had $1-3$ children parity, time from previous delivery was $>2$ years in $53.6 \%, 95.2 \%$ did not complete antenatal examinations, $95.8 \%$ had a body weight of $\geq 40 \mathrm{~kg}$ before pregnancy, $91.1 \%$ showed a $\geq 5$ kg increase in body weight during pregnancy, $45.8 \%$ had a high school education, $88.7 \%$ were housewives, hemoglobin level was $\geq 11 \mathrm{~g} / \mathrm{dL}$ in $63.1 \%$, and $53.0 \%$ did not consume heme-containing food daily. Only $53 \%$ of the participants consumed an adequate amount of iron, whereas the remaining $47 \%$ consumed less than the recommended amount of iron. Bivariate tests revealed that women who consumed an inadequate amount of iron during pregnancy had a 6.08-fold higher risk of low birth weight than women who consumed an adequate amount of iron during pregnancy.

Conclusions: The strongest risk factor for low birth weight was inadequate consumption of iron during pregnancy (odds ratio [OR] = 5.87; 95\%, CI: 2.76-12.49) followed by inadequate gestational age (OR = 4.27; 95\%, CI: 2.76-12.49).

Keywords: Anemia, Low birth weight, Iron tablets, Pregnancy.

(C) 2017 The Authors. Published by Innovare AcademicSciences PvtLtd. This is an open access article under the CC BY license (http://creativecommons. org/licenses/by/4. 0/) DOI: http://dx.doi.org/10.22159/ajpcr.2017.v10s5.23108

\section{INTRODUCTION}

Birth weight is an important indicator of a child's disease vulnerability and life expectancy. Newborns are classified into three categories on the basis of birth weight: $<2500$ g, 2500-3999 g, and $\geq 400$ g. According to the Department of Health of Indonesia (2008), low birth weight is defined as a birth weight of $<2500 \mathrm{~g}$, regardless of gestational age. In Indonesia, $11.1 \%$ of all babies born in 2010 had low birth weight, decreasing to $10.2 \%$ in 2013. In West Java, the prevalence of low birth weight in 2013 was $10.9 \%$, which was slightly higher than the national prevalence [1].

Low birth weight is one of the risk factors that contribute to infant mortality, especially in the prenatal period [2]. Indonesia Basic Health Survey (Riskesdas) [1] revealed a negative correlation between low birth weight and infant mortality. In addition to its association with higher infant mortality, low birth weight is also associated with a higher risk of infection, nutritional deficiency, disability, impaired growth and cognitive development, and the onset of chronic illness $[3,4]$.

Several factors such as maternal, pregnancy-related, and fetal factors can result in low birth weight. One such maternal factor is the maternal anemia status during pregnancy. The prevalence rate of anemia among pregnant women in Indonesia is $37.1 \%$. A prevalence rate of $\geq 40 \%$ is associated with severe public health issues [1]. Improvement in maternal hemoglobin levels during pregnancy results in an increase birth weight [5].

Women obtain their iron supplements from a variety of sources, including health-care facilities, when attending antenatal care check-ups, through self-purchase over the counter from drug shops, or through trained traditional birth attendants [6]. Iron deficiency is a common cause of anemia during pregnancy. The consumption of iron supplements with or without folic acid during pregnancy reduces the risk of anemia in pregnant women in the third trimester or at the time of delivery [5]. According to Riskesdas [1], the prevalence rate of iron consumption during pregnancy is $89.1 \%$, with marked variation in consumption duration. Among pregnant women who consumed iron supplements during their pregnancy, 33.3\% consumed them for $\geq 90$ days during pregnancy, $34.4 \%$ consumed them for $<90$ days, and as many as $21.4 \%$ of pregnant women could not recall how many tablets they consumed during pregnancy.

Iron tablet supplementation for at least 90 days during pregnancy is an important factor in ensuring elevated levels of maternal hemoglobin [7]. However, because various factors can result in non-compliance, adequate consumption of iron tablets is not always achieved. In a study conducted in Palu, Central Sulawesi, Restu et al. [8] reported that pregnant women who consumed iron tablets for $<90$ days during their pregnancy had a 3.82-fold higher risk of delivering low birth weight babies than pregnant women who consumed iron tablets for $\geq 90$ days during their pregnancy did. A study by Haider et al. [5] revealed that a 10-mg increase in daily iron intake during pregnancy could increase birth weight by approximately 15.1 (6.0-24.2) g.

To assess the adequacy of iron consumption during pregnancy and its effect on the risk of low birth weight, we conducted the present study in postpartum women in General Hospital, Depok city and Bekasi city, West Java. 


\section{METHODS}

This was a retrospective observational study with a case control design.

1. Cases: Pregnant women who delivered low birth weight babies $(<2500 \mathrm{~g})$ in RSUD Kota Depok and RSUD Kota Bekasi between September 1, 2015, and December 13, 2015.

2. Controls: Pregnant women who delivered babies with normal weight ( $\geq 2500$ g) in RSUD Kota Depok and RSUD Kota Bekasi between September 1, 2015, and December 13, 2015.

The minimal sample number was calculated to be 56 women per group according to the following formula (Lwanga and Lemeshow, 1991):

$\mathrm{n}=\left\{\mathrm{z}_{1-a} / 2 \sqrt{\left[2 \mathrm{P}_{2}^{*}\left(1-\mathrm{P}_{2}^{*}\right)\right]+\mathrm{z}_{1-\hat{a}}} \sqrt{\left[\mathrm{P}_{1}^{*}\left(1-\mathrm{P}_{1}^{*}\right)+\mathrm{P}_{2}^{*}\left(1-\mathrm{P}_{2}^{*}\right)\right]}\right\}^{2} /\left(\mathrm{P}_{1}^{*}-\mathrm{P}_{2}^{*}\right)^{2}$

Inclusion criteria were receipt of iron tablets from the government program during pregnancy and delivery in RSUD Kota Depok or RSUD Kota Bekasi between September 1, 2015, and December 13, 2015. The exclusion criteria were delivery of twins, morbidities such as pre-eclampsia, eclampsia, hypertension, heart disease, blood vessel disorder, diabetes mellitus, and infection, delivery of babies with congenital disorders, or denial of consent for inclusion in this study. A questionnaire was used as a reference in the interview. This questionnaire consisted of a combination of closed- and open-ended questions to obtain information about antenatal examination history, compliance with consumption of iron tablets, consumption habits and daily life, and characteristics not included in medical records such as body weight, height, and weight gain during pregnancy.

Data were also collected from the medical records of the participants and their babies. Secondary data collected from participants' medical records included participants' identities, characteristics, and hemoglobin levels. Participant's identities included name, medical records number, address, and phone number. Participant's characteristics included maternal age, gestational age, and parity; time from the previous delivery, education, and occupation secondary data collected from the medical records of the babies included weight, sex, and the presence or absence of congenital abnormalities.

Data were subjected to univariate, bivariate, and multivariate analysis. Univariate analysis was performed to obtain the frequency distribution of maternal characteristics on nominal or ordinal scales; maternal characteristics analyzed included age, gestational age, parity, time from previous delivery, education, occupation, height, weight before pregnancy, weight gain during pregnancy, hemoglobin level, antenatal examination status (complete or incomplete), and adequacy of iron tablet consumption during pregnancy. Bivariate analysis was performed using the Chi-square test $\left(\chi^{2}\right)$ with $\mathbf{a}=0.05$ and $95 \%$ confidence interval (CI) to determine the correlation between dependent and independent variables and to calculate the risk of each independent variable to a dependent variable using odds ratios (ORs). Multivariate analysis was performed using a logistic regression multivariate test to identify the variable that conferred the highest risk of low birth weight.

$\mathrm{OR}=\frac{\mathrm{a} / \mathrm{b}}{\mathrm{c} / \mathrm{d}}=\frac{\mathrm{ad}}{\mathrm{bc}}$

OR: Odds ratio (risk of incidence of low birth weight)

$\mathrm{a} / \mathrm{b}$ : Ratio of the number of exposed cases to the number of unexposed cases

c/d: Ratio of the number of exposed cases to the number of unexposed controls

Interpretation:

OR $<1$ : Exposure is a protective factor

$\mathrm{OR}=1$ : Exposure has no effect on case incidence

$\mathrm{OR}>1$ : Exposure is a risk factor.

\section{RESULTS AND DISCUSSION}

The number of cases and controls in this study was 56 and 112, respectively. Of these, 19 cases and 38 controls were from RSUD Kota Depok, whereas the other 37 cases and 74 controls were from RSUD Kota Bekasi. The characteristics of the study participants are described in Table 1; data regarding the consumption of iron tablets are described in Table 2. CI; LBWB, low birth weight baby; NBWB, normal birth weight baby, OR. As shown in Table 3, the Chi-square test revealed a correlation between iron tablet consumption and the incidence of low birth weight $(\mathrm{p}<0.05)$, with an OR of 6.081. This indicates that women who did not consume sufficient iron during their pregnancy had a 6.081-fold higher risk of low birth weight compared to women who consumed a sufficient amount of iron during their pregnancy.

\section{Effects of confounding factors on the incidence of low birth weight in RSUD Kota Depok and RSUD Kota Bekasi}

Table 4 summarized the results of bivariate Chi-square test and regression analysis conducted to determine the effect of confounding factors on the incidence of low birth weight. In this study, the correlation between maternal age at delivery and the incidence of low birth weight was not statistically significant ( $p>0.05)$. Among women who gave birth to low birth weight babies, the proportion of women with adequate $(\geq 37$ weeks) gestational age $(57.1 \%)$ was higher than that of women with inadequate ( $<37$ weeks) gestational age $(42.9 \%)$. The correlation between gestational age and low birth weight babies was statistically significant $(p=0.000)$. The incidence rate of low birth weight was higher in mothers with a birth range of $£ 2$ years $(51.8 \%)$ than in mothers with a birth range of $>2$ years $(48.2 \%)$. The correlation between birth range and low birth weight was not statistically significant $(\mathrm{p}=0.325)$. Among women who gave birth to low birth weight babies, the proportion of women with body weight $\geq 40 \mathrm{~kg}$ before pregnancy (92.9\%) was higher than that of women with body weight $<40 \mathrm{~kg}$ before pregnancy $(7.1 \%)$. The correlation between body weight before pregnancy and the incidence of low birth weight was not statistically significant $(p=0.172)$. Among women who gave birth to low birth weight babies, the proportion of women with height $\geq 146 \mathrm{~cm}$ was higher $(96.4 \%)$ than that of women with height $<146 \mathrm{~cm}(3.6 \%)$.

The correlation between maternal height and the incidence of low birth weight was not statistically significant $(\mathrm{p}=0.270)$. Among women who gave birth to low birth weight babies, the proportion of women with $\geq 5 \mathrm{~kg}$ weight gain was higher $(87.5 \%)$ than that of women with $<5 \mathrm{~kg}$ weight gain (12.5\%). The correlation between body weight gain during pregnancy and the incidence of low birth weight was not statistically significant $(\mathrm{p}=0.251)$. The proportion of women with high education (at least a high school education) was higher (55.4\%) than that of women with low education (44.6\%). The correlation between maternal education and the incidence of low birth weight was not statistically significant $(\mathrm{p}=0.263)$. An equal proportion of women had hemoglobin levels $<11 \mathrm{~g} / \mathrm{dl}$ and $11 \mathrm{~g} / \mathrm{dl}$ at delivery. The correlation between hemoglobin levels and the incidence of low birth weight was statistically significant $(\mathrm{p}=0.013)$. The proportion of women who underwent a complete antenatal examination (89.3\%) was higher than that of women who underwent an incomplete antenatal examination $(10.7 \%)$. The correlation between antenatal examination and the incidence of low birth weight was statistically significant $(\mathrm{p}=0.010)$. The proportion of women who did not consume heme-containing food everyday (57.1\%) was higher than that of women who consumed heme-containing food everyday (42.9\%). The correlation between the frequency of consumption of heme-containing food during pregnancy and the incidence of low birth weight was not statistically significant $(p=0.444)$.

Maternal age at delivery of $<20$ years and $>35$ years is one of the risk factors for low birth weight [9]. Maternal age $<20$ years is associated with immature reproductive organs for pregnancy, whereas maternal age $>35$ years is associated with decreased fertility of reproductive 
Table 1: Characteristics of study participants

\begin{tabular}{|c|c|c|c|}
\hline Description & LBWB n=56 (\%) & NBWB n=112 (\%) & Total $n=168(\%)$ \\
\hline \multicolumn{4}{|l|}{ Age (years) } \\
\hline$<20$ & $7(12.5)$ & $8(7.1)$ & $15(8.9)$ \\
\hline $20-35$ & $39(69.6)$ & $84(75.0)$ & $123(73.2)$ \\
\hline$>35$ & $10(17.9)$ & $20(17.9)$ & $30(17.9)$ \\
\hline \multicolumn{4}{|l|}{ Gestational age (weeks) } \\
\hline$<37$ & $24(42.9)$ & $16(14.3)$ & $40(23.8)$ \\
\hline$\geq 37$ & $32(57.1)$ & $96(85.7)$ & $128(76.2)$ \\
\hline \multicolumn{4}{|l|}{ Parity (number of children) } \\
\hline 0 & $23(41.0)$ & $32(28.6)$ & $55(32.7)$ \\
\hline $1-3$ & $31(55.4)$ & $72(64.3)$ & $103(61.3)$ \\
\hline$>3$ & $2(3.6)$ & $8(7.1)$ & $10(6.0)$ \\
\hline \multicolumn{4}{|l|}{ Birth range (years) } \\
\hline$\leq 2$ & $29(51.8)$ & $49(43.8)$ & $78(46.4)$ \\
\hline$>2$ & $27(48.2)$ & $63(56.2)$ & $90(53.6)$ \\
\hline \multicolumn{4}{|c|}{ Body weight before pregnancy (kg) } \\
\hline$<40$ & $4(7.1)$ & $3(2.7)$ & $7(4.2)$ \\
\hline$\geq 40$ & $52(92.9)$ & $109(97.3)$ & $161(95.8)$ \\
\hline \multicolumn{4}{|c|}{ Weight gain during pregnancy (kg) } \\
\hline$<5$ & $7(12.5)$ & $8(7.1)$ & $15(8.9)$ \\
\hline$\geq 5$ & $49(87.5)$ & $104(92.9)$ & $153(91.1)$ \\
\hline \multicolumn{4}{|l|}{ Height (cm) } \\
\hline$<146$ & $2(3.6)$ & $9(8.0)$ & $11(6.5)$ \\
\hline$\geq 146$ & $54(96.4)$ & $103(92.0)$ & $157(93.5)$ \\
\hline \multicolumn{4}{|l|}{ Education } \\
\hline SD (primary school) & $5(8.9)$ & $17(15.2)$ & $22(13.1)$ \\
\hline SMP (junior high school) & $20(35.7)$ & $23(20.6)$ & $43(25.6)$ \\
\hline SMA (senior high school) & $23(41.1)$ & $54(48.2)$ & $77(45.8)$ \\
\hline D3 (associate degree) & $2(3.6)$ & $10(8.9)$ & $12(7.2)$ \\
\hline S1 (bachelor's degree) & $6(10.7)$ & $8(7.1)$ & $14(8.3)$ \\
\hline \multicolumn{4}{|l|}{ Hemoglobin levels (g/dL) } \\
\hline$<11$ & $28(50)$ & $34(30.4)$ & $62(36.9)$ \\
\hline$\geq 11$ & $28(50)$ & $78(69.6)$ & $106(63.1)$ \\
\hline \multicolumn{4}{|l|}{ Antenatal examination } \\
\hline Incomplete & $6(10.7)$ & $2(1.8)$ & $8(4.8)$ \\
\hline Complete & $50(89.3)$ & $110(98.2)$ & $160(95.2)$ \\
\hline \multicolumn{4}{|c|}{ Consumption of heme-containing food } \\
\hline Not everyday & $32(57.1)$ & $57(50.9)$ & $89(53.0)$ \\
\hline Everyday & $24(42.9)$ & 55 (49.1) & $79(47.0)$ \\
\hline \multicolumn{4}{|l|}{ Occupation } \\
\hline Housewife & $49(87.5)$ & $100(89.3)$ & 149 (88.7) \\
\hline Government employee & $2(3.6)$ & $3(2.7)$ & $5(3.0)$ \\
\hline Private sector employee & $5(8.9)$ & $7(6.2)$ & $12(7.1)$ \\
\hline Entrepreneur & $0(0)$ & $2(1.8)$ & $2(1.2)$ \\
\hline \multicolumn{4}{|l|}{ Delivery location } \\
\hline RSUD Bekasi & $37(66.1)$ & $74(66.1)$ & $111(66.1)$ \\
\hline RSUD Depok & $19(33.9)$ & $38(33.9)$ & $57(33.9)$ \\
\hline \multicolumn{4}{|l|}{ Sex of baby } \\
\hline Female & $24(42.9)$ & $45(40.2)$ & $69(41.1)$ \\
\hline Male & $32(57.2)$ & $67(59.8)$ & $99(58.9)$ \\
\hline
\end{tabular}

LBWB: Low birth weight baby, NBWB: Normal birth weight baby

Table 2: Consumption of iron tablets during pregnancy

\begin{tabular}{llll}
\hline $\begin{array}{l}\text { Consumption } \\
\text { of iron tablets }\end{array}$ & $\begin{array}{l}\text { LBWB } \\
\mathbf{n = 5 6}(\mathbf{\%})\end{array}$ & $\begin{array}{l}\text { NBWB } \\
\mathbf{n = 1 1 2}(\mathbf{\%})\end{array}$ & $\begin{array}{l}\text { Total } \\
\mathbf{n = 1 6 8}(\mathbf{6})\end{array}$ \\
\hline Insufficient & $42(75.0)$ & $37(33.0)$ & $79(47.0)$ \\
Sufficient & $14(25.0)$ & $75(67)$ & $89(53.0)$ \\
\hline
\end{tabular}

LBWB: Low birth weight baby, NBWB: Normal birth weight baby

organs [9]. The risk of low birth weight in women aged $<20$ years is almost 2-fold greater than that in women aged 20-29 years [10]. Inadequate pregnancy age was one of the factors associated with low birth weight. Inadequate pregnancy age is closely related with immature fetal growth and organ development. A study conducted by Elshibly and Schmalisch [11] in Sudan revealed a strong relationship between gestational age and the incidence of low birth weight. Similarly, Restu et al. [8] also reported a significant relationship between gestational age and the incidence of low birth weight.
Time from previous delivery affects maternal hormonal and nutritional conditions. A short birth range is one of the risk factors for low birth weight because the mother's condition is still considered to be insufficiently recovered and her nutritional status is suboptimal [9]. Maternal anthropometry such as body weight before pregnancy and height plays an important role in fetal development. Low body weight before pregnancy and weight gain during pregnancy are important predictors of fetal development [10].

A high education status is considered to increase access to information and health services that can improve the quality of maternal and infant health. The higher the level of education, the easier it is for mothers to understand the concept of a healthy lifestyle. Restu et al. [8] found a significant correlation between educational level and the incidence of low birth weight $(\mathrm{OR}=2.38 ; 95 \%, \mathrm{CI}: 1.12-5.03)$. Anemia is one of the risk factors for low birth weight. A study by Ghimire and Ghimire [12] in Nepal revealed a greater frequency of low birth weight in mothers with anemia (22\%) than in non-anemic mothers (9\%). Restu et al. [8] 
Table 3: Effect of iron tablet consumption during pregnancy on birth weight

\begin{tabular}{|c|c|c|c|c|c|c|}
\hline \multirow[t]{2}{*}{ Iron tablet consumption } & \multicolumn{2}{|l|}{ Birth weight } & \multirow[t]{2}{*}{$\mathbf{p}$} & \multirow[t]{2}{*}{ OR } & \multicolumn{2}{|l|}{$95 \% \mathrm{CI}$} \\
\hline & LBWB $n=56(\%)$ & NBWB n=112 (\%) & & & Minimum & Maximum \\
\hline Insufficient & $42(25)$ & 37 (22) & 0.000 & 6.081 & 2.955 & 12.515 \\
\hline Sufficient & $14(8.3)$ & $75(44.6)$ & & & & \\
\hline
\end{tabular}

Table 4: Effect of confounding factors on low birth weight, determined using a bivariate test

\begin{tabular}{|c|c|c|c|c|}
\hline Description & LBWB $n=56(\%)$ & NBWB n=112 (\%) & Total $n=168(\%)$ & p (significant) \\
\hline \multicolumn{5}{|l|}{ Age } \\
\hline High risk ( $<20$ years and more than 35 years) & $17(30.4)$ & $28(25.0)$ & $45(26.8)$ & \multirow{2}{*}{0.460} \\
\hline Low risk (age between 20 and 35 years) & $39(23.2)$ & $84(75.0)$ & $123(73.2)$ & \\
\hline \multicolumn{5}{|l|}{ Gestational age (weeks) } \\
\hline$<37$ & $24(42.9)$ & $16(14.3)$ & $40(23.8)$ & \multirow[t]{2}{*}{0.000} \\
\hline$\geq 37$ & $32(57.1)$ & $96(85.7)$ & $128(76.2)$ & \\
\hline \multicolumn{5}{|l|}{ Parity } \\
\hline Risk (nulliparity and more than 3 deliveries) & 47 (83.9) & $86(76.8)$ & $133(79.2)$ & \multirow[b]{2}{*}{0.283} \\
\hline No risk (multiparity with $1-3$ deliveries) & $9(16.1)$ & $26(23.2)$ & $35(20.8)$ & \\
\hline \multicolumn{5}{|l|}{ Birth range (years) } \\
\hline$\leq 2$ & $29(51.8)$ & $49(43.8)$ & $78(46.4)$ & \multirow{2}{*}{0.325} \\
\hline$>2$ & $27(48.2)$ & $63(56.2)$ & $90(53.6)$ & \\
\hline \multicolumn{5}{|l|}{ Weight before pregnancy (kg) } \\
\hline$<40$ & $4(7.1)$ & $3(2.7)$ & $7(4.2)$ & \multirow[t]{2}{*}{0.172} \\
\hline$\geq 40$ & $52(92.9)$ & $109(97.3)$ & $161(95.8)$ & \\
\hline \multicolumn{5}{|l|}{ Weight gain during pregnancy (kg) } \\
\hline$<5$ & $7(12.5)$ & $8(7.1)$ & $15(8.9)$ & \multirow[t]{2}{*}{0.251} \\
\hline$\geq 5$ & $49(87.5)$ & $104(92.9)$ & 153 (91.1) & \\
\hline \multicolumn{5}{|l|}{ Height (cm) } \\
\hline$<146$ & $2(3.6)$ & $9(8.0)$ & $11(6.5)$ & \multirow{2}{*}{0.270} \\
\hline$\geq 146$ & $54(96.4)$ & $103(92.0)$ & $157(93.5)$ & \\
\hline \multicolumn{5}{|l|}{ Education Level } \\
\hline Low education (primary school and junior high school) & $25(44.6)$ & $40(35.7)$ & 65 (38.7) & \multirow[t]{2}{*}{0.263} \\
\hline $\begin{array}{l}\text { High education (senior high school, associate degree, and } \\
\text { bachelor's degree) }\end{array}$ & $31(55.4)$ & $72(64.3)$ & $103(61.3)$ & \\
\hline \multicolumn{5}{|l|}{ Hb level $(\mathrm{g} / \mathrm{dL})$} \\
\hline$<11$ & $28(50)$ & $34(30.4)$ & $62(36.9)$ & \multirow[t]{2}{*}{0.013} \\
\hline$\geq 11$ & $28(50)$ & $78(69.6)$ & $106(63.1)$ & \\
\hline \multicolumn{5}{|l|}{ Antenatal Examination } \\
\hline$<4$ times & $6(10.7)$ & $2(1.8)$ & $8(4.8)$ & \multirow[t]{2}{*}{0.010} \\
\hline 4 or more times & $50(89.3)$ & $110(98.2)$ & $160(95.2)$ & \\
\hline \multicolumn{5}{|l|}{ Consumption of heme-containing food } \\
\hline Not everyday & $32(57.1)$ & $57(50.9)$ & $89(53.0)$ & \multirow[t]{2}{*}{0.444} \\
\hline Everyday & $24(42.9)$ & 55 (49.1) & $79(47.0)$ & \\
\hline
\end{tabular}

Table 5: Effect of confounding factors on low birth weight, determined using a logistic regression

\begin{tabular}{|c|c|c|c|c|c|c|}
\hline \multirow[t]{2}{*}{ Logistic regression steps } & \multirow[t]{2}{*}{ B } & \multirow[t]{2}{*}{ Wald } & \multirow[t]{2}{*}{ Significant } & \multirow[t]{2}{*}{$\operatorname{Exp}(B)$} & \multicolumn{2}{|c|}{ 95\%, CI for $\operatorname{Exp}(B)$} \\
\hline & & & & & Lower & Upper \\
\hline \multicolumn{7}{|l|}{ Step 1} \\
\hline Iron tablet consumption & 1.798 & 14.646 & 0.000 & 6.036 & 2.404 & 15.157 \\
\hline Gestational age & 1.474 & 12.147 & 0.000 & 4.369 & 1.907 & 10.011 \\
\hline Antenatal examination & 1.302 & 1.929 & 0.165 & 3.678 & 0.585 & 23.114 \\
\hline Weight before pregnancy & 0.859 & 1.035 & 0.309 & 2.362 & 0.451 & 12.363 \\
\hline Hemoglobin levels & -0.234 & 0.261 & 0.610 & 0.791 & 0.322 & 1.943 \\
\hline Constant & -2.077 & 37.372 & 0.000 & 0.125 & & \\
\hline \multicolumn{7}{|l|}{ Step 2} \\
\hline Iron tablet consumption & 1.666 & 18.199 & 0.000 & 5.292 & 2.461 & 11.379 \\
\hline Gestational age & 1.475 & 12.257 & 0.000 & 4.373 & 1.914 & 9.989 \\
\hline Antenatal examination & 1.302 & 1.943 & 0.163 & 3.677 & 0.589 & 22.941 \\
\hline Weight before pregnancy & 0.831 & 0.979 & 0.322 & 2.295 & 0.443 & 11.897 \\
\hline Constant & -2.105 & 39.030 & 0.000 & 0.122 & & \\
\hline \multicolumn{7}{|l|}{ Step 3} \\
\hline Iron tablet consumption & 1.689 & 18.882 & 0.000 & 5.412 & 2.527 & 11.590 \\
\hline Gestational age & 1.452 & 11.847 & 0.001 & 4.272 & 1.869 & 9.766 \\
\hline Antenatal examination & 1.365 & 2.180 & 0.140 & 3.915 & 0.640 & 23.964 \\
\hline Constant & -2.070 & 38.728 & 0.000 & 0.126 & & \\
\hline \multicolumn{7}{|l|}{ Step 4} \\
\hline Iron tablet consumption & 1.770 & 21.161 & 0.000 & 5.873 & 2.762 & 12.485 \\
\hline Gestational age & 1.452 & 12.073 & 0.001 & 4.271 & 1.883 & 9.689 \\
\hline Constant & -2.050 & 38.273 & 0.000 & 0.129 & & \\
\hline
\end{tabular}


found that low maternal hemoglobin $(<11 \mathrm{~g} / \mathrm{dL})$ was a risk factor for low birth weight (OR $=3.45 ; 95 \%$, CI: 1.59-7.49). Consistent with this, Sharma et al. [13] found that maternal hemoglobin levels of $<11 \mathrm{~g} / \mathrm{dL}$ were significantly associated with low birth weight (adjusted OR $=0.51$; 95\%, CI: 0.24-1.07).

Early antenatal examination in pregnancy is enormously beneficial to fetal growth and development, as well as maternal health. Risk factors for low birth weight can be detected during antenatal examination, enabling the implementation of strategies to reduce this risk. A study by Fourn et al. [14] of factors associated with low birth weight found that an adequate antenatal examination was a protective factor against the incidence of low birth weight $(\mathrm{OR}=0.85 ; 95 \%, \mathrm{CI}$ : 0.69-0.99). Consistent with this, a study conducted by Sistiarani [15] at Banyumas Hospital revealed a significant correlation between antenatal examination and the incidence of low birth weight $(\mathrm{p}=0.001$; OR $=5.85 ; 95 \%$, CI: 1.9 17.88).

Consumption of heme-containing food can fulfill the nutritional needs of mothers for iron during pregnancy. Poor nutritional intake during pregnancy may cause a deficiency of micronutrients needed for fetal growth and development. Sharma et al. [13] found that lack of nutritious food intake during pregnancy was significantly associated with the incidence of low birth weight (adjusted OR $=1.99$; 95\%, CI: 1.28-3.10). On the basis of bivariate test results, we included the following variables in logistic regression analysis: Consumption of iron tablets, gestational age, antenatal examination status, body weight before pregnancy, and hemoglobin levels. The results are shown in Table 5.

The results of the logistic regression multivariate tests revealed that inadequate consumption of iron tablets during pregnancy was the strongest risk factor for low birth weight (OR $=5.873 ; 95 \%$, CI: 2.762 $12.485)$, followed by gestational age (OR $=4.271 ; 95 \%$, CI: $2.762-$ 12.485).

\section{CONCLUSION}

Women who consumed an inadequate amount of iron had a 6.08fold higher risk of delivering low birth weight babies than women who consumed an adequate amount of iron during their pregnancies. The strongest risk factors for the incidence of low birth weight were inadequate consumption of iron during pregnancy $(\mathrm{OR}=5.87$; $95 \%$,
CI: 2.76-12.48), followed by inadequate gestational age (OR $=4.27$; 95\%, CI: 2.76-12.49).

\section{REFERENCES}

1. Badan Pusat Statistik. Survei Demografi dan Kesehatan Indonesia 2012. Jakarta: Badan Pusat Statistik; 2012.

2. Carrera JM, Carbonel X, Fabre E. Recommendation and Guidelines for Perinatal Medicine. Barcelona: Matres Mundi; 2007.

3. United Nations Children's Fund and World Health Organization. Low Birthweight: Country, Regional and Global Estimates. New York: UNICEF; 2004.

4. Valero De Bernabé J, Soriano T, Albaladejo R, Juarranz M, Calle ME, Martínez D, et al. Risk factors for low birth weight: A review. Eur J Obstet Gynecol Reprod Biol 2004;116(1):3-15.

5. Haider BA, Olofin I, Wang M, Spiegelman D, Ezzati M, Fawzi WW. Anaemia, prenatal iron use, and risk of adverse pregnancy outcomes: Systematic review and meta-analysis. BMJ 2013;346:1-19.

6. Dibley MJ, Titaley CR, d'Este C, Agho K. Iron and folic acid supplements in pregnancy improve child survival in Indonesia. Am J Clin Nutr 2012;95:1-11

7. Habib F, Alabdin EH, Alenazy M, Nooh R. Compliance to iron supplementation during pregnancy. J Obstet Gynaecol 2009;29(6):487-92.

8. Restu S, Dasuki D, Nurdiati RD. The influence of iron supplementation in pregnant women to the occurrence of Low Birth Weight (LBW) babies in Pali, Central Sulawesi. J Med Sci 2014;46(1):41-51.

9. Manuaba AC, Manuaba IB, Manuaba IB. Ilmu Kebidanan, Penyakit Kandungan dan KB Untuk Pendidikan Bidan. $2^{\text {nd }}$ ed. Jakarta: EGC; 2010 .

10. Sharma M, Mishra S. Effects of maternal health and nutrition on birth weight of infant. Int J Sci Res 2012;3(6):856-8.

11. Elshibly EM, Schmalisch G. Relationship between maternal and newborn anthropometric measurements in Sudan. Pediatr Int 2009;51(3):326-31.

12. Ghimire RH, Ghimire S. Maternal and fetal outcome following severe anaemia in pregnancy: Results from nobel medical college teaching hospital, Biratnagar, Nepal. J Nobel Med Coll 2012;2(1):22-6.

13. Sharma SR, Giri S, Timalsina U, Bhandari SS, Basyal B, Wagle K, et al. Low birth weight at term and its determinants in a tertiary hospital of Nepal: A case-control study. PLoS One 2015;10(4):e0123962.

14. Fourn L, Ducic S, Séguin L. Factors associated with low birth weight: A multivariate analysis. Sante 1999;9(1):7-11.

15. Sistiarani C. Faktor Maternal dan Kualitas Pelayanan Antenatal Yang Berisiko Terhadap Kejadian Berat Badan Lahir Rendah (BBLR). Thesis. Semarang: Universitas Diponegoro; 2008. 